\title{
Facial allograft transplants: where's the catch?
}

B E White and I Brassington

J. Med. Ethics 2008;34;723-726

doi:10.1136/jme.2007.023150

Updated information and services can be found at:

http://jme.bmj.com/cgi/content/full/34/10/723

These include:

References This article cites 7 articles, 4 of which can be accessed free at: http://jme.bmj.com/cgi/content/full/34/10/723\#BIBL

Rapid responses You can respond to this article at:

http://jme.bmj.com/cgi/eletter-submit/34/10/723

Email alerting Receive free email alerts when new articles cite this article - sign up in the box at service the top right corner of the article

Notes

To order reprints of this article go to:

http://journals.bmj.com/cgi/reprintform

To subscribe to Journal of Medical Ethics go to:

http://journals.bmj.com/subscriptions/ 


\title{
Facial allograft transplants: where's the catch?
}

\author{
B E White, ${ }^{1}$ I Brassington ${ }^{2}$
}

${ }^{1}$ Medical Student, University College London, London, UK; ${ }^{2}$ CSEP/iSEl, School of Law, University of Manchester, Manchester, UK

Correspondence to: Dr I Brassington, CSEP/iSEl, School of Law, University of Manchester, Oxford Road, Manchester M13 9PL, UK; iain brassington@manchester.ac.uk

Received 19 September 2007 Revised 18 December 2007 Accepted 9 January 2008

\begin{abstract}
Face transplantation - or, more properly, facial allograft transplantation (FAT) — generates much public interest and academic debate. In this paper, we suggest that it is up to opponents of FAT to make the case for its impermissibility. We allow that there is a number of apparently strong arguments that might be deployed against FAT. However, all but one of these turn out not to be compelling after examination. The remaining argument is not so easily dismissed - but its central point is fairly workaday and certainly does not tell us anything about FAT in particular. Therefore, qua argument about facial transplant surgery, it fails to hit its target. Overall, we conclude that a compelling case against FAT remains to be made.
\end{abstract}

Face transplants are big news when they happen: one needs only to think of the media coverage of Isabelle Dinoire. They promote vigorous argument, not all of which is illuminating; indeed, it is not even clear that face transplant is the best term to describe the procedure. Agich and Siemionow prefer the term facial allograft transplantation (FAT) to describe the procedure, which transplants soft tissue but not bone ${ }^{1}$ - therefore many of the major components of the face, but not the face itself. We keep their terminology here.

Clinically speaking, FAT is just another graft. However, attached to any externally visible surgery are additional ethical complications. Freeman and Abou Jaoudé, writing in the Journal of Medical Ethics, put forward a comprehensive account of the objections to FAT and conclude that "the case for [FAT] has not yet been made". ${ }^{2}$ Such confidence is a touch puzzling, because it would seem straightforward to say that if the procedure is deemed to be clinically appropriate, that alone constitutes the case. Still, the case for FAT faces a number of potential rebuttals when we look beyond what is merely clinically indicated. The strongest of these revolve around issues of identity and the possibility of valid consent being obtained for the procedure. Nevertheless, as we shall argue, they are not sufficient to demonstrate that there are serious and unique moral problems with FAT.

As a prelude to the argument proper, there is a couple of important points that we take as axiomatic. First, FAT is not an emergency or lifesaving treatment. FAT promises a treatment for disfigurement and (according to its proponents) a means of enhancing the quality of a life; but it would be possible to keep a patient alive without having to perform FAT. Second, FAT is not really reconstructive: it does not attempt to provide the illusion that nothing has happened by rebuilding the face that has been lost, so much as to provide a substitute for it. These points inform our argument.

\section{OBJECTIONS BASED ON PERSONAL IDENTITY}

Freeman and Abou Jaoudé say that a face is a person's most intimate and most individual characteristic. ${ }^{2}$ We are reluctant to accept this, since one might consider other parts of our bodies as more intimate and no part less individual than the face. Others, though, have made claims that seem to be related but that are less bold and more tenable. One worry might be something along the lines that, by performing FAT, we would be taking part of one individual's identity and using it to overwrite another's: several people have made claims suggesting that FAT may impact on an individual's personal identity. ${ }^{3}$ Such a claim makes most sense when "personal identity" is understood as relating to a person's ability to identify with himself or herself and his or her body, rather than to what it is that makes him or her the same person over time: the preoperative Dinoire survived her operation.

Following up concerns about possible difficulties in identifying with one's body or parts thereof, we might note that Toombs suggestsin a slightly different, but similar enough, context-that "[a]ltered patterns of movement or changes in physical appearance cause one to experience the body as unfamiliar and unrecognisable-as no longer one's own". ${ }^{5}$ If one's sense of identity is strongly bound to the (visible) body, then that identity looks as though it might possibly be compromised or subsumed by FAT. But although there is an apparently reasonable prima facie ground to worries about the threat that FAT might pose to personal identity, the success of these claims in grounding an objection to FAT is not a given. In fact, the worries are baseless.

Worries about replacing one person's face with another's-and, to the extent that faces and identity are related, one person's identity with another's-are misplaced for two reasons. First, FAT does not take anyone's identity. To the extent that identity is associated with the face at all, it would seem safe to assume that it has already been undermined by the disfigurement the FAT seeks to treat, and is therefore not there to be taken. Second, because FAT transplants only the soft tissue, recipients would not really end up with even a part of another's appearance or identity. They would not gain another's identity so much as gain a new, third, one-which, again, they would have done anyway, courtesy of the disfigurement. This point speaks to Freeman and Abou Jaoudé's concern that "the recipient will have neither a "normal" appearance nor a unique identity": 2 if uniqueness is really important, concerns can be put to rest, because a post-FAT face will be no less unique than anyone else's. 
The other claims, though, are more substantial. People can experience all kinds of problems in identifying with their bodies, and can, and do, become seriously alienated from them; transplantation is not the only reason for this, but it does figure in the list. In this context, Toombs seems to have hit on a legitimate concern. FAT is, all else being equal, just another transplant that ought to be no more or less liable to cause identification problems; we may, therefore, expect that a person who has had FAT (or any kind of facial surgery) would be about as likely to have problems identifying with the new tissue as would a recipient of a more conventional transplant. However, in respect of the face, all else is not equal. The face is not just the location of organs useful for ingestion, respiration and vision; it is also the part of the body that, more than any other, allows us to identify and express ourselves to others. It is the medium through which others see us, and-indirectly, perhaps-it is crucial to the way that we see ourselves. Thus it would appear that we can distinguish between the barely clinical aspects of the face and its existentially important aspects; and we can admit that to be alienated from one's face may lead to a much more profound and distressing alienation from ourselves.

But while this is no small worry, it has to be taken in context. Granted, a person may end up profoundly alienated from the new face after FAT, and this may have profound existential implications. But it ought not to be forgotten that a person would presumably be a candidate for FAT only in those cases in which that person was already alienated from his or her face. For the sake of argument, we can allow that post-FAT alienation will be somehow different from that caused by the disfigurement. But the choice is still between two comparable kinds of alienation; either way, alienation of some sort seems inevitable.

The slight dent in this supposition might be the thought that if someone remains disfigured, this in some way shields the person from alienation from the face. How might such a claim work? Well, here is part of what the French National Consultative Ethics Committee for Health and Sciences (CCNE) has to say about possible alienation from the face:

\footnotetext{
Before we look anew into a mirror every morning, we already have some anticipation of what we shall behold: a representation of that face, fashioned by the innumerable previous occasions on which we have seen it. However, if it so happens that the face that the mirror reflects does not correspond to that anticipation, we are just as likely to think: "this is not me", at least as much as: "so, this is me". When a person whose face is momentarily deformed (by dental surgery, allergic reaction, a blow, or trauma, or even at a time of great weariness or because there is some reluctance to accept ageing features) looks into a mirror, surely the first thing that comes to mind is "I do not recognise myself. This is not me" (p153).
}

This last sentence seems not to be true in at least some cases. To see ourselves, wounded, is different from seeing someone else entirely; me wounded is still me. But if the allograft is good, the face in the mirror might be that of a different person altogether, and so give rise to problems. Call this attempt to salvage identity-based objections to FAT the "good allograft objection".

Is the good allograft objection compelling? Probably not. For one thing, there is no reason to suppose that individuals could not learn to live with their reconfigured face in more or less the same way as they would be forced to learn to live with a disfigured one-especially if we subscribe to a narrative view of personal identity, in which what we are is a product of the constant recapitulation of the events that befall us and our reactions to them. ${ }^{7}$ Alienation might well evaporate. Indeed, experiences from hand transplants cited by Swindell (p507) $)^{3}$ would suggest that it does; and if for hands-bearing in mind that hands are also a highly visible part of the body that often contribute to our understanding of ourselves and the way we interact with others-why not other external tissues such as the face?

Even if it is impossible to learn to live wholly comfortably with a reconfigured face, we might plausibly characterise FAT as offering at least the chance of some relief; if it does not achieve complete equanimity, there is still no a priori reason to think that the recipient's situation would be made any worse. Even if it is fair to expect distress at seeing an unexpected face in the mirror, it also seems fair to point out that FAT candidates will also experience distress arising from not being able to chew, breathe comfortably, blink or carry out at least some everyday activities, and from the mere fact of being disfigured. FAT, there is reason to believe, could relieve this distress, or else there would be no reason at all — compelling or not-to provide it. If we are playing a consequentialist game (as would appear to be the case if the nexus of concern is with problems arising from the surgery) this relief ought to be weighed against problems of alienation; the balance could well tip in favour of FAT.

It ought not to be forgotten, too, that the choice that patients and medical teams face is not between FAT and nothing, since the disfigured might also face repeated grafts and the like. Such alternative treatment options do not attract the same controversy, but FAT may well represent an improvement on them. ${ }^{1}$

Moreover, we ought not to neglect the fact that the World Health Organization's definition of health, for better or worse, is inclusive enough to cover social well-being. And, for as long as mainstream voices are willing to accept that the World Health Organization's definition is at least partly right, it is not too underhand to bring it to the table for consideration. Now, the way that one looks is important. On this basis, having any disfigurement at all is likely to impact deleteriously on wellbeing; a minimally disfigured face, though, will be one in which this impact will be minimised. It is reasonable to assume that FAT would be offered only to those whose appearance it promised to improve; therefore it would promise an improvement of social well-being, and this, too, ought to be taken into account. Maybe the improvement in social well-being would not wholly counterbalance potential existential problems in any actual case. But such counterbalancing is possible in principle; therefore we ought not to accept a priori the assertion that the existential cost of FAT is intolerably high.

Along the same lines, there might be psychosocial problems associated with a person's appearance changing radically as a result of FAT. But, even granted that there may be important problems associated with the new face to be confronted both by the patient and by those around the patient, they are not significantly different from the problems that we may expect in relation to the disfigurement that the FAT is supposed to remedy. If a radical alteration in someone's face is sufficient to cause social problems great enough to impact on well-being, how that alteration comes about need not be relevant. Finally, since FAT is elective and at least potentially therapeutic, the problems of identification should be fewer and smaller than would arise from the initial disfigurement-at least from the point of view of the patient, whose welfare presumably is more important than the feelings of third parties.

\section{WANTS, NEEDS AND SURGERY}

So it would appear that the identification problem is actually not all that problematic when seen in context. However, the 
consideration that minimises the identification worry-that persons must already be seriously distressed by their current facial condition in order to consider candidacy for FAT-is exactly that which gives rise to another: to wit, there may be a disjunction between a (potential) patient's wants and the patient's needs. Huxtable and Woodley characterise the need for FAT as being only indirectly related to the nature of a given disfigurement: a small blemish might cause serious distress in one person, and a major disfigurement, less distress in another. ${ }^{8}$ In such cases, there is reason to think that the person with the greater distress is more likely to seek surgical intervention. At the same time, the person in more clinical need-allowing that we can say that there is such a need-may want the intervention less. There is, those authors claim, therefore a potential disjunction between wanting and needing FAT.

One manifestation of this disjunction is the worry, articulated by Huxtable and Woodley, that, in a "beauty-fixated society" (p507), ${ }^{9}$ the disfigured may be pressurised into seeking FAT that they do not need when there are less risky treatments available. Given the risks, they suggest that "[w] hether autonomy and thus individual choice should govern in this matter is open to debate" and that some kind of paternalism may not be utterly unwarranted. ${ }^{9}$ We shall return to the themes of autonomy and a want/need mismatch in a moment.

For the time being, though, there is something to be said about the phrase "beauty-fixated society", which seems needlessly pejorative: even if one can flourish without it, beauty is a very good thing. There is no reason to suppose that those who pursue it are any more susceptible to social pressures than those who pursue high-income or high-prestige jobs. We would not characterise would-be hedge-fund managers or professors of neurosurgery as the flotsam of a materialistic society. There is no corresponding reason to characterise those who pursue beauty as such. Besides, FAT will probably not make people beautiful. It will make them look normal and forgettable - that is its virtue.

Now, back to the theme of autonomy. Clarifying this will also help remove the problem with wanting and needing FAT. Huxtable and Woodley seem to have mischaracterised what autonomy can offer. Autonomy, and the protection thereof, is not about agents being able to dictate what treatments are to be on the menu; what it does do is provide moral protection for the ability to choose something or nothing from that menu. So simply wanting FAT-or any other procedure-is not enough, even bulked out with appeals to autonomy, for that procedure to be morally mandated. Add to this, though, the fairly straightforward thought that it behoves a surgeon to do no harm without warrant, and it is pretty clear that FAT will be (or ought to be) offered only to those considered to be in the most need-not to the most desirous.

We do not have to be too restrictive when it comes to deciding how we ought to judge that need. For one thing, there is a tenable line of thought that says that any need is such only in the context of some project that we might pursue: no one needs a medical procedure except to the extent that it is a necessary criterion of achieving some end. This end may be idiosyncratic or universally shared, but in neither case is it inherently important. ${ }^{10} \mathrm{~A}$ need, on this understanding, is a species of desire. To this extent, the person who wants (needs?) surgery for a small blemish and the person who wants (needs?) it to rectify a major disfigurement are in the same boat. The only decision that a surgeon has to make concerns whether the want (need?) is sufficient to warrant the risks of the procedure. If he thinks it is, he may choose to offer it; if not, not.
Sometimes it will be clinical need that carries the weight, sometimes distress; which is the more important can vary from patient to patient without impropriety. There need not be any problem about the less disfigured being offered surgery before the more disfigured.

\section{THE CATCH-22 PROBLEM}

Huxtable and Woodley suggest that their want/need disjunction can be characterised further as a catch-22 problem:

The potential psychological and physical effects and the likely level of media interest (and even intrusion) certainly suggest that the recipient [of FAT] will need to be a pretty robust character. Yet, if that intuition is correct, will such an individual want (or "need"?) the procedure [...]?

[... I]f you are robust enough to submit yourself to the procedure and all it might entail, you may be least likely to want it; if, on the other hand, you do desire the new face, you may be less able to cope with the risks posed by this procedure.'

We have no quibble with the need for the procedure being characterised in terms of distress: as we stated earlier, it is not likely that FAT will be a life-saving operation. Now, the group of FAT candidates who are, in these terms, psychologically robust does not present any problem. There may be any number of people whose condition is such as would lead a medical professional to the justified belief that surgery would be in their clinical best interests-but none of them is de facto obliged to act according to this medic's belief and have the surgery, and none of them is obliged to think that strict clinical interests tell the whole story anyway.

It is the non-robust group that presents the problem. This worry is not really neutralised by the considerations concerning need outlined a moment ago, since, wherever one stands on the wants/needs axis, and even though it seems reasonable to assume that one would need FAT only in the context of even a minimal project like "leading a tolerable life", the mere fact that one's disfigurement might be intolerable might well sap psychological strength. Nevertheless, it is a problem that is overplayed.

The reason for this is that Huxtable and Woodley have assumed that the fact that one finds one's disfigurement highly distressing is in itself sufficient to indicate that one is likely to be highly distressed by all that FAT brings with it. This is straightforwardly fallacious. There is no reason at all why a person's distress at $A$ should tell us anything at all about the way that person responds to $B$. Mention of "all that [FAT] might entail" is simply too vague to be able to make any predictions such as are implied here; and if we try to narrow down what "all that FAT might entail" means, there is nothing to force anyone to accept that all, or even any, such entailments are problematic.

But let us be generous to the catch-22 problem, and recast it a little: again, those who can most plausibly be said to need the operation are those whom we might reasonably expect to be the most distressed by their current disfigurement; but to this we add the claim that it is precisely these people who are least likely to be able to make the kind of balanced and clear-headed decision that we would ordinarily expect to form part of the consent process for any medical procedure, and certainly a procedure as radical and experimental as FAT: "an individual who is seriously compromised by their disfigurement might not pass the [ability-to-cope] test and might hence be ruled ineligible." Moreover, just because FAT is not emergency treatment, consent would, we can assume, be necessary. At the 
same time, persons sufficiently psychologically robust to give consent for the procedure in the first place are precisely the persons whom we might expect not to be so distressed by their condition, and so less in need-and there is something paradoxical about allowing for those who are in less need a procedure that we would not allow for those in greater need.

But even here, the problem is not all that great. For sure, distress may sometimes preclude consent, but it need not always do so; so we can answer the point much as we answered the last point. Distress will not necessarily undermine the ability to give consent.

On the other hand, we can concede the possibility that there will be certain people whose distress at their disfigurement is such as to mean that consent is impossible. But the possibility that there are such people will not tell us anything in particular about FAT: all it does is illustrate the workaday problems that arise from dealing with any patient too distressed to give consent to a procedure. In such situations, a medic has two options: either he can provide the procedure without consent, possibly in the belief that the therapeutic benefit of the procedure will, by removing its cause, remove the distress; or he can refuse to provide the procedure on the basis that there is no consent and life is not in imminent danger from either the distress or the disfigurement. From the manner in which Huxtable and Woodley are prepared to allow debate of the balance between autonomy and paternalism, they may not have too many problems with the first option. If this is accurate, though, they have not provided a reason to forbear from FAT. Quite the opposite: they have provided a reason to perform it. After all, if it is distress that concerns us, it is presumably caused by the disfigurement that FAT promises to ameliorate. Removing the disfigurement would, in this picture, reliably remove the distress. Refusing to make this move risks generating the disquieting claim that because of (not despite, mark) a person's distress, we ought not to remove the source of that distress. If, on the other hand, Huxtable and Woodley's preferred option is the latter, and FAT ought not to be provided until clear-headed consent is possible, then, unless there is proof that facial disfigurement is necessarily and uniquely corrosive to one's ability to consent, they have said nothing about FAT: instead, they have simply made a fairly trivial point about consent.

\section{THE CASE AGAINST FAT: NOT PROVEN}

It is false to say that the case for FAT has not been made; it is true to say that it is not immune to criticism. However, the most promising criticisms do not, in the end, undermine the case for FAT. The procedure is risky, and it may be counterproductive. But the same applies to many innovative treatments, and it is not enough to undermine their use. By the same token, it ought not to undermine that of FAT.

Competing interests: None.

\section{REFERENCES}

1. Agich GJ, Siemionow M. Until they have faces: the ethics of facial allograft transplantation. J Med Ethics 2005;31:707-9.

2. Freeman $\mathbf{M}$, Abou Jaoudé P. Justifying surgery's last taboo: the ethics of face transplants. J Med Ethics 2007;33:76-81.

3. Swindell JS. Facial allograft transplantation, personal identity and subjectivity. J Med Ethics 2007;33:449--53.

4. Robertson J. Face transplants: enriching the debate. Am J Bioeth 2004;4:32-3.

5. Toombs SK. What does it mean to be somebody? In: Cherry MJ, ed. Persons and their bodies: rights, responsibilities, relationships. Philosophy and Medicine, vol 50. Springer, 1999. SpringerLink: Doi 10.1007/0-306-46866-2 1 (2002):89.

6. National Consultative Ethics Committee for Health and Life Sciences. Composite tissue allotransplantation (CTA) of the face (full or partial facial transplant). Opinion no. 82. Paris: Comité Consultatif National d'Ethique, 2004. http://www. ccne-ethique.fr/docs/en/avis082.pdf (accessed 16 July 2008).

7. Olafson F. What is a human being? A Heideggerian view. Cambridge: Cambridge University Press, 1995:153.

8. Huxtable R, Woodley J. (When) will they have faces? J Med Ethics 2006;32:403-4

9. Huxtable R, Woodley J. Gaining face or losing face? Framing the debate on face transplants. Bioethics 2005;19:505-22.

10. Brassington I. Body art and medical need. J Med Ethics 2006;32:13-16. 